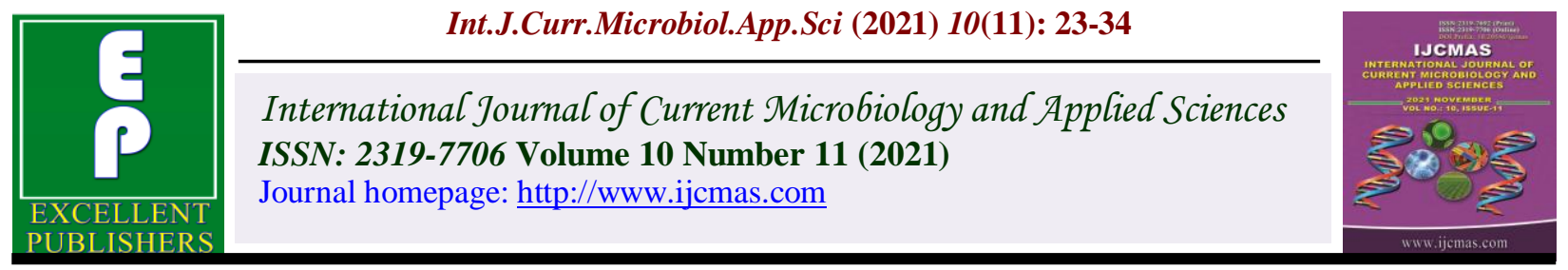

\title{
Isolation and Screening of Plant Growth Promoting Rhizobacteria from the Rhizospheric Soil of Wheat (Triticum aestivum) from Lower Western Himalayan Zone of Himachal Pradesh
}

\author{
Vijay Kumar*, Indu, Richa, Sahil Kumar and Diksha Sehajpal
}

Department of Microbiology, School of Pharmaceutical and Health Sciences, Career Point University, Hamirpur-176041, Himachal Pradesh, India

*Corresponding author

\section{A B S T R A C T}

\begin{tabular}{|l|}
\hline Ke y w o r d s \\
Wheat, \\
Nutrition, \\
Rhizosphere, \\
PGPR and \\
P-solubilization \\
\hline Article Info \\
\hline Received: \\
04 October 2021 \\
Accepted: \\
29 October 2021 \\
Available Online: \\
10 November 2021 \\
\hline
\end{tabular}

\section{Keywords}

Wheat,

Nutrition,

Rhizosphere,

PGPR and

P-solubilization

Article Info

Received:

04 October 2021

Accepted:

Available Online:

10 November 2021
The bacteria that colonize the plant's rhizosphere are known as PGPR. The rhizospheric region is the area under the ground surface that is linked with plant roots. PGPR bacteria are free-living bacteria that colonize plant roots and have positive impacts on plant growth. The objectives of this paper were to isolate and identify the most powerful PGPR, as well as to assess their efficacy in terms of P-solubilization, $\mathrm{HCN}$ generation, and lytic enzyme activity (protease). A total of 11 bacterial isolates were identified in the Hamirpur district of Himachal Pradesh. All isolates were tested for a variety of plant growth-promoting characteristics, including phosphate solubility, HCN production and protease production. On PVK agar, 8 of the 11 isolates tested positive for P-solubilization in the $5-20 \mathrm{~mm}$ zone. One bacterial isolate exhibited positive hydrogen cyanide activity in the event of HCN generation. In the case of lytic enzyme activity, 7 bacterial isolates were positive for protease production.

\section{Introduction}

Wheat (Triticum aestivum) is the most important grain for human survival (Kumar and Sharma, 2017). After rice, it is India's second most grown cereal crop. Wheat is an essential staple grain for the people of northern India. It's a Poaceae family plant that grows every year (Gramineae). Wheat flour is commonly used by humans to make Chapaties and pasta goods, while straw is utilised as animal feed and packaging material. It's utilised in the manufacturing of starch, gluten, malt, and distilled spirits. Wheat includes $70 \%$ carbohydrate, $13 \%$ protein, 1.7 percent lipids, 2.7 percent minerals, $2 \%$ fibre, and $12 \%$ moisture (Oyewole et al., 2016). Wheat, when consumed as a whole grain, provides a variety 
of nutrients and dietary fibre, as well as a reduced risk of a variety of illnesses, including coronary heart disease, stroke, cancer, and diabetes (Shewry P R, Hey S J, 2015). Wheat is cultivated on around 30 million hectares in India, with a yield of 106.21 million tons in 2019-20. (The Economic Times, 2020).Himachal Pradesh, a Himalayan state in India's northwestern Himalayas, is one of the country's leading wheat producers (Kumar et al., 2020). Kloepper and Schroth coined the term PGPR in 1978. (Verma et al., 2019). Plant growth-promoting rhizobacteria are bacteria that colonize plant roots and promote plant development by a number of processes, including phosphate solubilization, siderophore generation, $\mathrm{HCN}$ production, and biological nitrogen fixation (Vejan et al., 2016).

The Rhizosphere was initially coined by Hiltner to describe the small zone of soil around the root where root activities increase microbe populations, commonly known as the "Rhizosphere effect" (Das et al., 2013).The rhizosphere is known as a "microbe storehouse" because it is a rich source of microorganisms and microbial activity (Kundan et al., 2015). These bacteria's main functions are to: (a) provide nutrients to crops; (b) stimulate plant development, for example, by producing phytohormones; (c) enhance soil structure; and (d) protect plants from diseases (Kundan et al., 2015).The PGPR mechanism employs both direct and indirect approaches.

Rhizobacteria, on the other hand, are indirectly involved by decreasing the impact of diseases and developing systemic resistance (Bhattacharyya, P. N., and Jha, D. K., 2012). Bacillus and Azospirillum are two common genera participating in PGPR (Mangmang et al., 2015). Phosphorous is an important plant nutrient that helps in the growth and development of plants. After nitrogen, it is the world's second-largest crop nutritional supplement (Kumar and Sharma, 2017). Microorganisms play an important role in biogeochemical processes such as soil phosphorus mineralization, solubilization, and transformation (Heijden et al., 2008).

As a frequent secondary metabolite, rhizospheric pseudomonads generate hydrogen cyanide, a gas that is known to severely influence root metabolism and root development and is a viable and ecologically friendly strategy for pathogen biological control (Kumar \& Sharma, 2017).

HCN will most likely block the electron transport chain and give energy to the cell, resulting in the death of the cells (Kundan et al., 2015). Several PGPR inoculants are presently available for purchase, and they serve an important role in encouraging development. PGPR inoculants can be used as biofertilizers or phytopathogen antagonists, making them a viable alternative to chemical fertilizers and pesticides (Kumar et al., 2020).

\section{Materials and Methods}

\section{Collection of rhizospheric soil sample}

The soil sample used for PGPR isolation was collected from rhizosphere of wheat (Triticum aestivum) from Lower West Central Outer Himalayan zone from Hamirpur district of Himachal Pradesh, India. Sampling was done in the month of January \& February of the year 2021. Sample was stored in plastic bottles/bags loosely tied to ensure sufficient aeration and to prevent moisture loss from the soil samples(Modi et al., 2017).

\section{Isolation of potential plant growth promoting rhizobacteria}

PGPR isolates were isolated from the rhizospheric soil sample by serial dilution and spread plate method using King's B agar 
medium at $28^{\circ} \mathrm{C}$ (Singh \& Lal, 2016). Pikovskayas agar used for phosphate solubilizing bacteria (Pikovskaya's 1948) and King's B agar for Pseudomonas sp. (King et al., 1954).

\section{Colony morphology and pigment production}

Colony morphology (form, elevation, margin, shape \& surface) and the production of

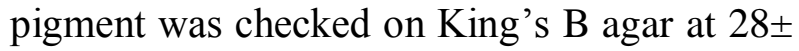
$2^{\circ} \mathrm{C}$ after 24 to 48 hours (Kumar et al., 2020).

Characterization of selected isolates for various PGP attributes

\section{Phosphate solubilization}

The ability of bacteria to solubilize phosphorus was tested on Pikovskaya's agar plates. Each bacterial culture was spot inoculated in the centre of Pikovskaya's agar plates containing tricalcium phosphate as insoluble phosphate source (Kumar et al., 2020). The plates were incubated at $28^{\circ} \mathrm{C}$ for 5-7 days and halozone development around the bacterial growth was observed.

\section{HCN}

All the isolates were screened out for the formation of hydrogen cyanide. Cultures were streaked on nutrient agar plates amended with glycine $(1.4 \mathrm{~g} / \mathrm{l})$. Whatman No. 1 filter paper strips were soaked in $0.5 \%$ picric acid followed by $2 \%$ sodium carbonate and were placed in the lids of each petriplates (Kumar et al., 2020).

Plates were sealed with parafilm and incubated at 28 degrees Celsius for four days. Plates were examined for changes in filter paper colour from yellow (-) to light brown $(++)$ to brown $(+++)$ to dark brown $(++++)$ (Kumar et al., 2020).

\section{Lytic enzyme}

\section{Protease production}

All isolates were tested for protease production on skim milk agar (1 percent skim milk was employed in the nutrient agar medium) and autoclaved separately before pouring, both flasks were combined, and plates were poured (Modi et al., 2017). Spot inoculation of each bacterial culture in the centre of skim milk agar plates was used. We observed the clear zone around the colony after 24-48 hours of incubation at $28^{\circ} \mathrm{C}$. The diameter of clear zones generated around the colony after 48 hours of incubation at $28^{\circ} \mathrm{C}$ is used to measure proteolytic activity (Kumar $e t$ al., 2020).

\section{Results and Discussion}

\section{Collection of rhizospheric soil sample}

The rhizospheric soil sample for PGPR's isolation was collected from rhizosphere of wheat (Triticum aestivum) crop from Hamirpur district of Himachal Pradesh, India located at the altitude above mean sea level in Tal $(300 \mathrm{~m})$. All the rhizospheric soil sample was collected in clean and sterilized sampling bottles and stored in refrigerator in laboratory (Nelson, 2004).

\section{Isolation of PGPR from rhizospheric soil}

\section{Hamirpur District}

PGPR isolates were isolated from the rhizospheric soil sample by serial dilution and spread plate method using King's B agar medium at $28{ }^{\circ} \mathrm{C}$. The total viable count of rhizobacteria of wheat (Triticum aestivum) from Tal site of Hamirpur is depicted in Table 1. The total rhizobacterial population on King's B agar medium (264 x 105) microbial population at Tal. King's B agar is a non- 
selective medium generally used for the isolation of Pseudomonas species. The variation in the population of rhizobacteria may be attributed to location, age of plant, variety, time of sampling, physio-chemical and biological properties of the soil and environmental conditions of the locations. According to Tamilarasi et al., (2008), the varied degree of population found in plant roots is due to the influence of the chemical composition of individual plant root exudates on microorganisms. In total, 11 PGPR isolates were isolated on King's B agar medium. The morphological characters of bacterial isolates, i.e. pigmentation, form, elevation, margin, shape, and gram-reaction were noted down and presented in Fig 2.

\section{Tal site}

The pigmentation of colonies of bacterial isolates from Tal varied from white, cream, off-white and whitish-creamish. The majority of isolates were white $(55 \%)$ in color, $9 \%$ were cream in color, $27 \%$ of isolates were offwhite and $9 \%$ were whitish-creamish in color. $73 \%$ were circular, $18 \%$ were punctiform and $9 \%$ were round in form.

Out of total isolates, $46 \%$ isolates were raised while $45 \%$ were flat and $9 \%$ had convex elevation. $62 \%$ of isolates were entire and $38 \%$ had undulate margins. $82 \%$ of the bacterial isolates were gram-negative, while $18 \%$ were found to be gram-positive. $82 \%$ of the isolates were bacilli and $18 \%$ had a cocci shape.

\section{Phosphate solubilization}

Phosphate solubilization activity shown by bacterial isolates from the Tal site was expressed in the range of 8 to $15 \mathrm{~mm}$ in diameter of halozone on PVK agar plate. Out of eleven isolates, 8 isolates showed phosphate solubilization. Maximum Psolubilization was shown by the isolates Tl-1 $(15 \mathrm{~mm})$, followed by Tl-4 $(12 \mathrm{~mm})$ and Tl-10 (11mm) (Table 4). Gupta (2012) also reported that the population of phosphate-solubilizing microorganisms, in general, varied from 20$24 \%$ of the total population, but in some soils, it may be as high as $85 \%$ of the total population. In other studies, conducted by Kundu et al., (2002), it was reported that about $16 \%$ of the total bacterial population in the rhizosphere of wheat was P-solubilizer.

\section{HCN Production}

Isolates of PGPR from Tal showed HCN production on nutrient agar medium amended with glycine. Out of eleven isolates, maximum production of $\mathrm{HCN}(+++)$ was shown by Tl-1 to change the colour of filter paper strip yellow (-) to brown (+++). No $\mathrm{HCN}$ production was shown by other isolates from Tal (Table 5). A similar study indicates that $\mathrm{HCN}$ production is established to be a common trait of Pseudomonas $(88.89 \%)$ and Bacillus (50\%) within the rhizospheric soil of wheat, a biocontrol metabolite in Pseudomonas species (Saharan and Nehra, 2011).

Table.1 Population density of rhizobacteria on King's B agar media from Tal site of Hamirpur District of Himachal Pradesh

\begin{tabular}{|c|c|c|c|}
\hline \multirow{2}{*}{$\begin{array}{c}\text { Site of } \\
\text { rhizospheric soil } \\
\text { sample collection }\end{array}$} & \multicolumn{3}{|c|}{ Total viable count on King's B agar media } \\
\cline { 2 - 4 } & $\mathbf{1 0}^{-4}$ & Dilutions & cfu/g soil x 10 \\
\hline Tal & 264 & $\mathbf{1 0}^{\mathbf{- 6}}$ & $264 \times 10^{5}$ \\
\hline
\end{tabular}


Table.2 Morphological characteristics of bacteria isolated from site Tal

\begin{tabular}{|c|c|c|c|c|c|c|c|}
\hline $\begin{array}{c}\text { Sr. } \\
\text { No. }\end{array}$ & Isolate & Pigment & Elevation & Margin & Form & $\begin{array}{c}\text { Gram } \\
\text { reaction }\end{array}$ & Shape \\
\hline 1 & Tl-1 & White & Flat & Entire & Round & - & Bacilli \\
\hline 2 & Tl-2 & Cream & Flat & Entire & Circular & - & Bacilli \\
\hline 3 & Tl-3 & White & Raised & Entire & Circular & - & Bacilli \\
\hline 4 & Tl-4 & White & Convex & Undulate & Punctiform & + & Bacilli \\
\hline 5 & Tl-5 & Whitish-cream & Flat & Entire & Circular & + & Cocci \\
\hline 6 & Tl-6 & Off- white & Flat & Entire & Circular & - & Bacilli \\
\hline 7 & Tl-7 & Off- white & Flat & Entire & Circular & - & Bacilli \\
\hline 8 & Tl-8 & White & Raised & Undulate & Circular & - & Cocci \\
\hline 9 & Tl-9 & White & Raised & Undulate & Circular & - & Bacilli \\
\hline 10 & Tl-10 & Off- white & Raised & Entire & Punctiform & - & Bacilli \\
\hline 11 & Tl-11 & white & Raised & Entire & Circular & - & Bacilli \\
\hline
\end{tabular}

Table.3 Purification of PGPR's isolated from rhizospheric soil of wheat (Triticum aestivum)

\begin{tabular}{|c|c|c|}
\hline S.No. & Isolate & Site \\
\hline $\mathbf{1}$ & Tl-1 & \multirow{3}{*}{ Tal } \\
\hline $\mathbf{2}$ & Tl-2 & \multirow{2}{*}{ Tal } \\
\hline $\mathbf{3}$ & Tl-3 & \\
\hline $\mathbf{4}$ & Tl-9 & \\
\hline
\end{tabular}

Table.4 Evaluation of different PGP attributes of rhizobacteria isolated from site Tal

\begin{tabular}{|c|c|c|}
\hline Sr. No. & Isolate & $\begin{array}{c}\text { Phosphate- solubilization } \\
\text { plate }(\mathbf{m m} \text { dia) }\end{array}$ \\
\hline 1 & Tl-1 & 15 \\
\hline 2 & Tl-2 & 0 \\
\hline 3 & Tl-3 & 9 \\
\hline 4 & Tl-4 & 12 \\
\hline 5 & Tl-5 & 11 \\
\hline 6 & Tl-6 & 0 \\
\hline 7 & Tl-7 & 10 \\
\hline 8 & Tl-8 & 8 \\
\hline 9 & Tl-9 & 0 \\
\hline 10 & Tl-10 & 11 \\
\hline 11 & Tl-11 & 8 \\
\hline
\end{tabular}


Table.5 Evaluation of different PGP attributes of rhizobacteria isolated from site Tal

\begin{tabular}{|c|c|c|}
\hline Sr. No. & Isolate & $\begin{array}{c}\text { HCN } \\
\text { Change of color (Yellow to brown) }\end{array}$ \\
\hline 1 & Tl-1 & +++ \\
\hline 2 & Tl-2 & - \\
\hline 3 & Tl-3 & - \\
\hline 4 & Tl-4 & ++++ \\
\hline 5 & Tl-5 & - \\
\hline 6 & Tl-6 & - \\
\hline 7 & Tl-7 & - \\
\hline 8 & Tl-8 & +++ \\
\hline 9 & Tl-9 & - \\
\hline 10 & Tl-10 & - \\
\hline 11 & Tl-11 & - \\
\hline
\end{tabular}

*HCN production colour change from Yellow to brown to dark brown

Yellow: - ; Light brown: ++ ; Brown: +++; Dark brown: ++++

Table.6 Evaluation of different PGP attributes of rhizobacteria isolated from site Tal

\begin{tabular}{|c|c|c|}
\hline Sr. No. & Isolate & $\begin{array}{c}\text { Protease production } \\
\text { plate (mm dia) }\end{array}$ \\
\hline 1 & Tl-1 & 13 \\
\hline 2 & Tl-2 & 0 \\
\hline 3 & Tl-3 & 8 \\
\hline 4 & Tl-4 & 10 \\
\hline 5 & Tl-5 & 0 \\
\hline 6 & Tl-6 & 0 \\
\hline 7 & Tl-7 & 14 \\
\hline 8 & Tl-8 & 11 \\
\hline 9 & Tl-9 & 6 \\
\hline 10 & Tl-10 & 9 \\
\hline 11 & Tl-11 & 0 \\
\hline
\end{tabular}

Fig.1 Collection of rhizospheric soil sample of wheat (Triticum aestivum) from Tal sites of Hamirpur District (H. P.)
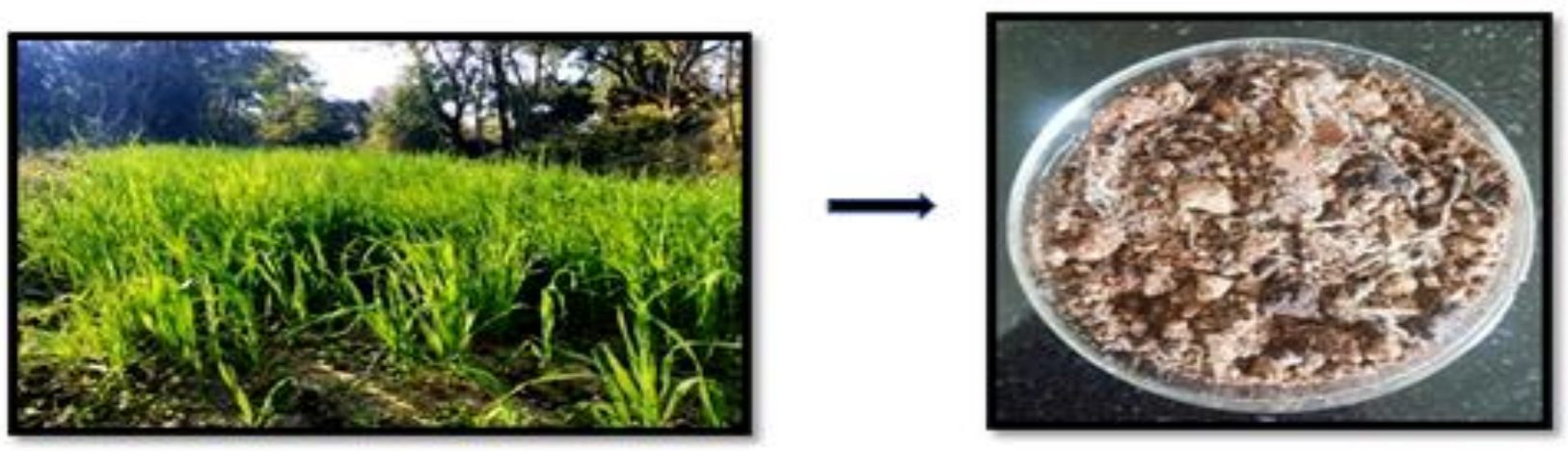
Fig.2 Morphological characteristics of rhizobacterial isolates from site Tal

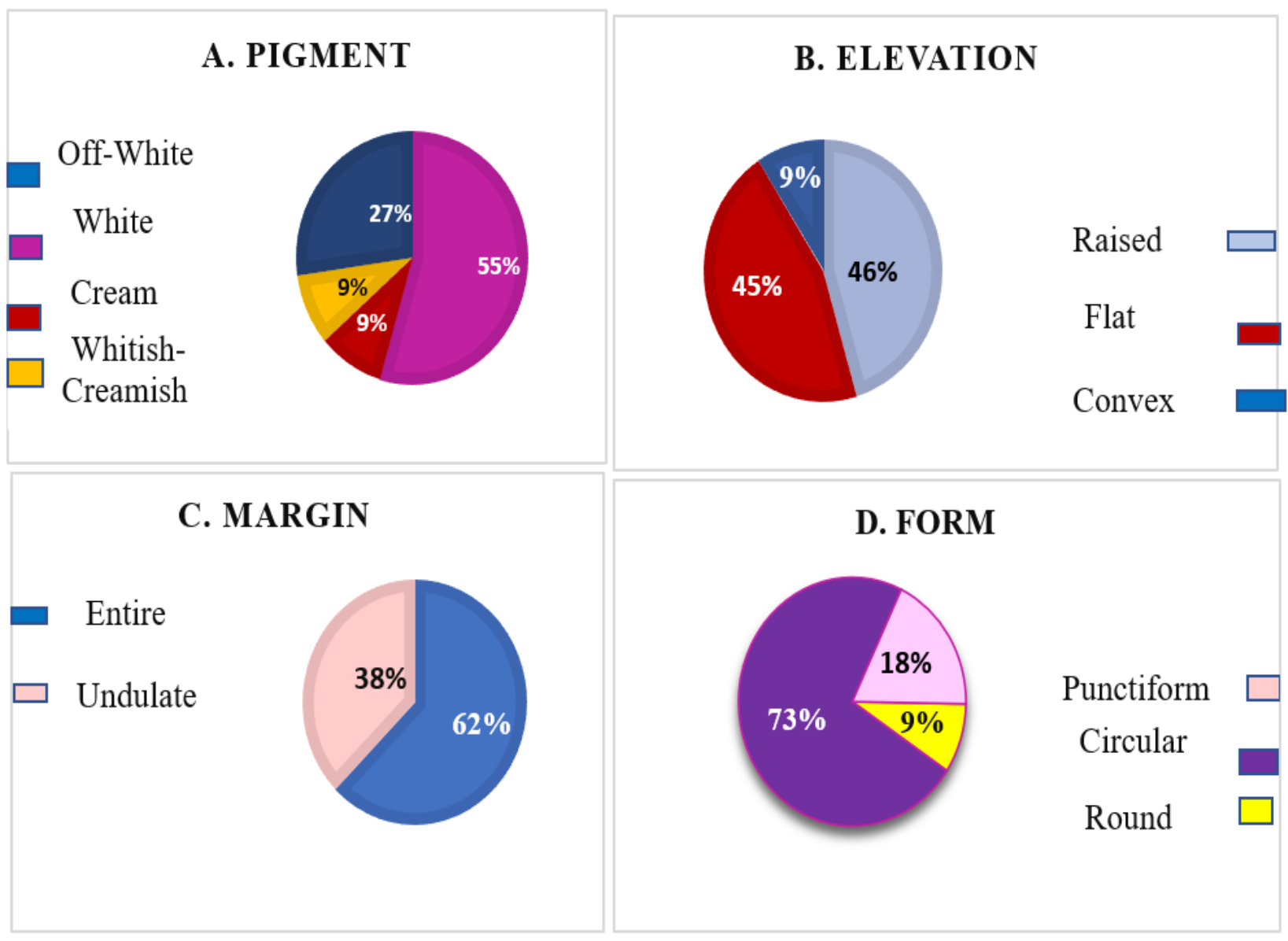

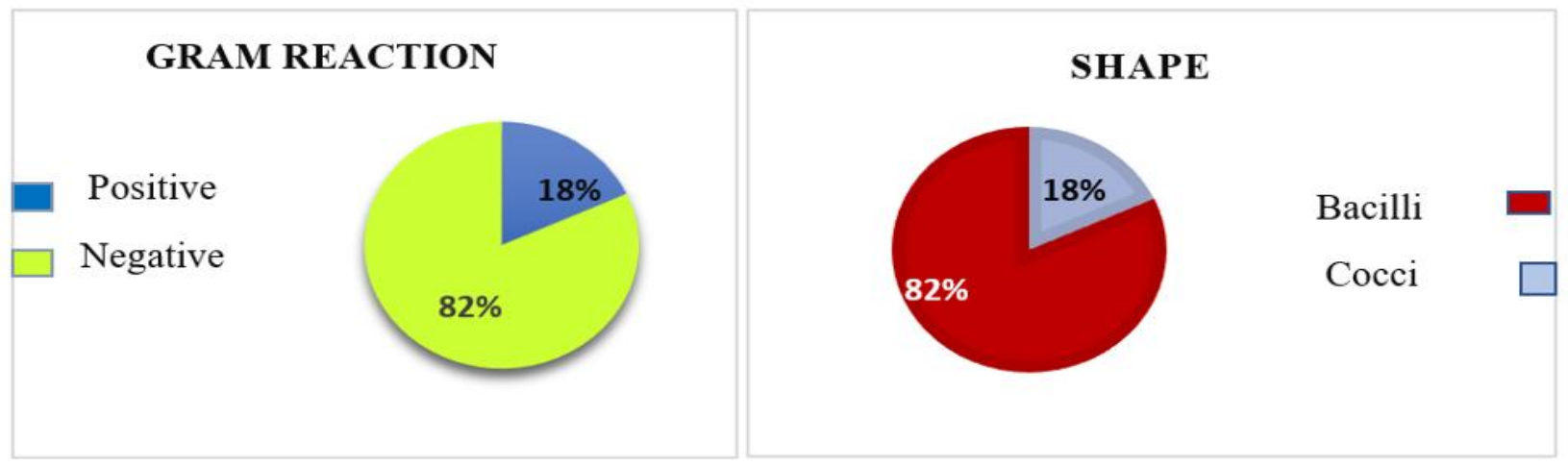


Fig.3 Total viable count of rhizobacteria from the rhizospheric soil of wheat on King's B agar medium from Hamirpur district
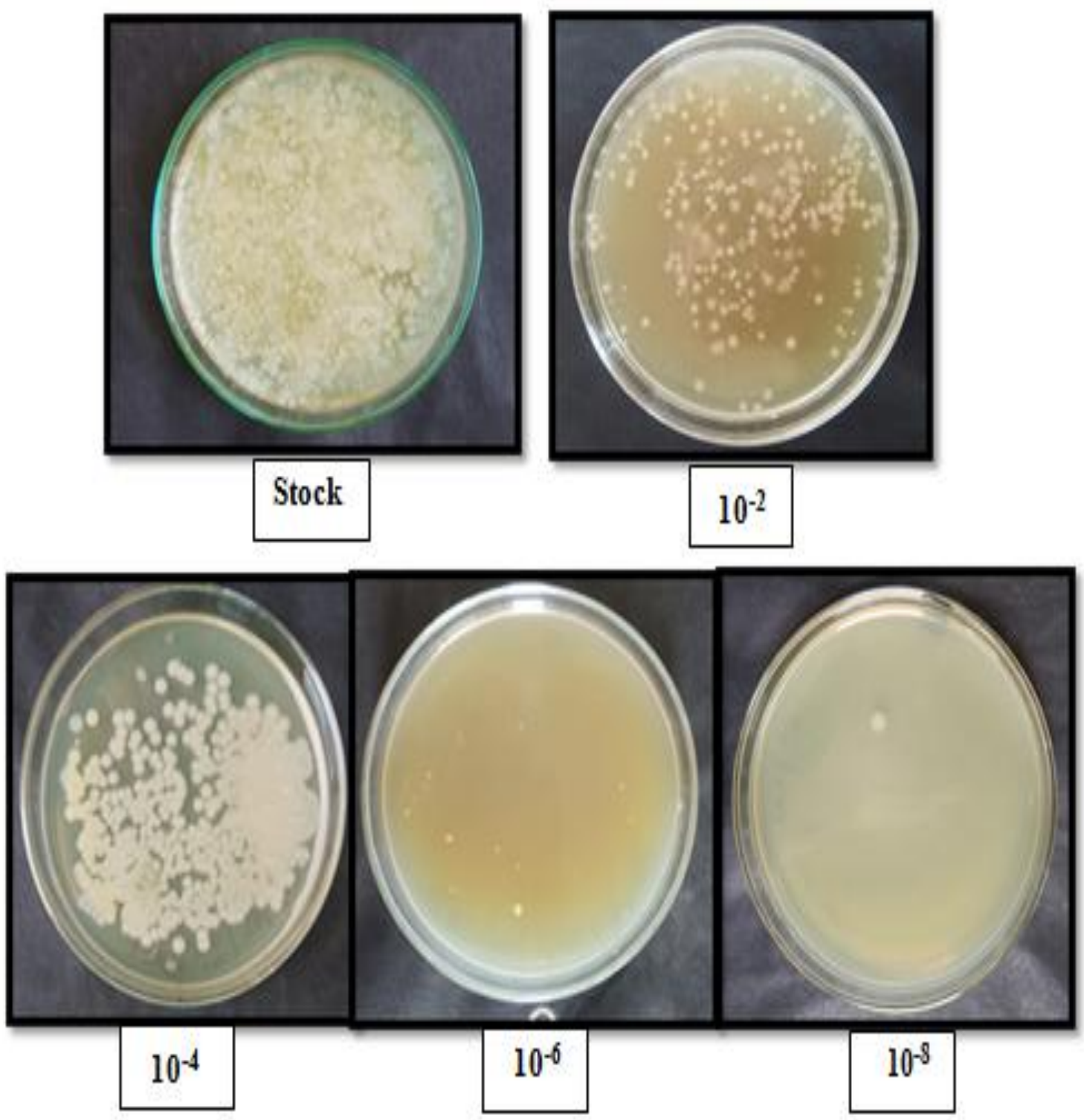
Fig.4 Purified bacterial isolates from Tal site of Hamirpur District (H.P.)
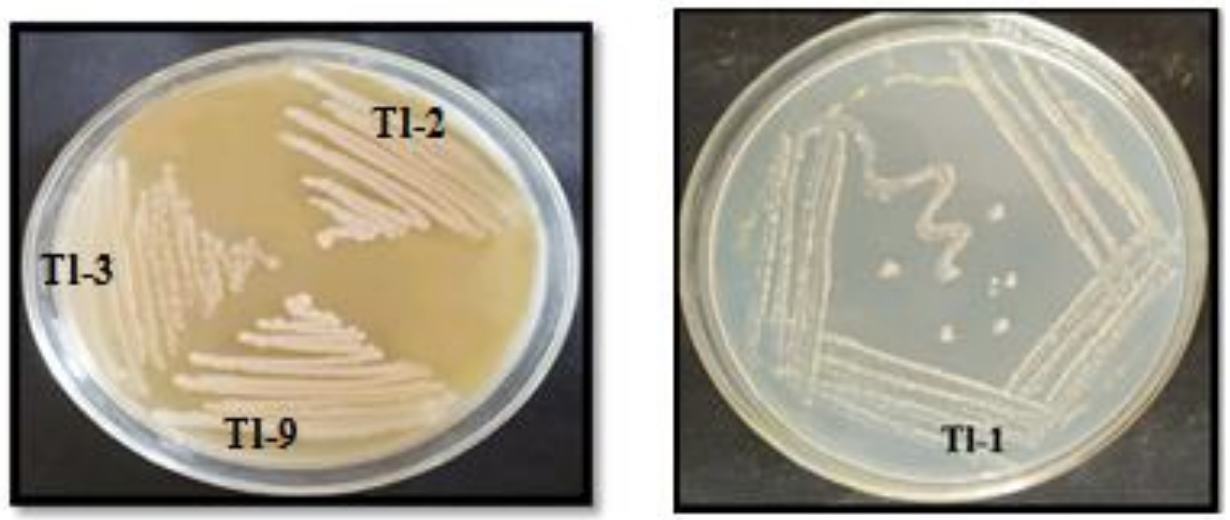

Fig.5 Phosphate solubilization activity shown by bacterial isolates from Tal site of Hamirpur District

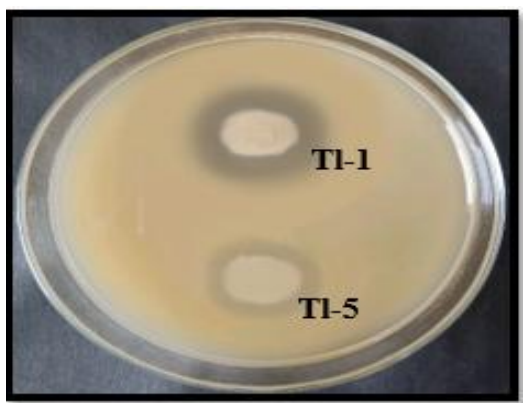

Fig.6 (A) Show the negative control of HCN; (B) Show the positive control of HCN

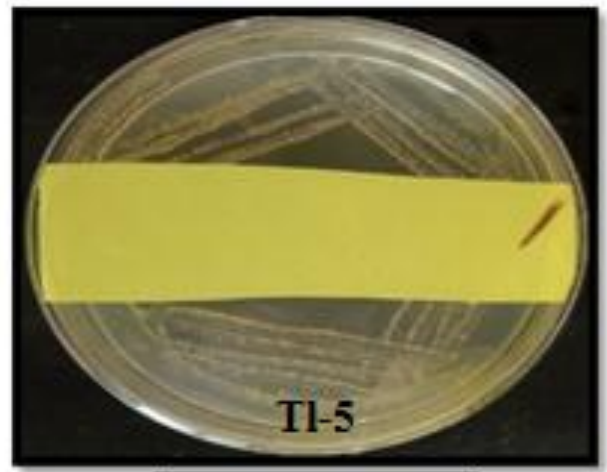

A) Negative

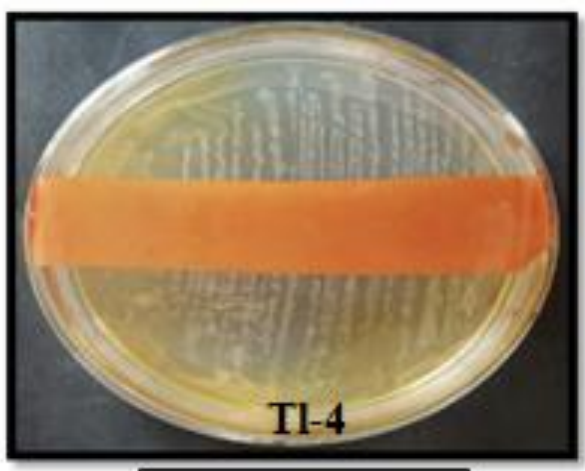

B) Positive 
Fig.7 Protease activity shown by bacterial isolates from Tal site of Hamirpur District

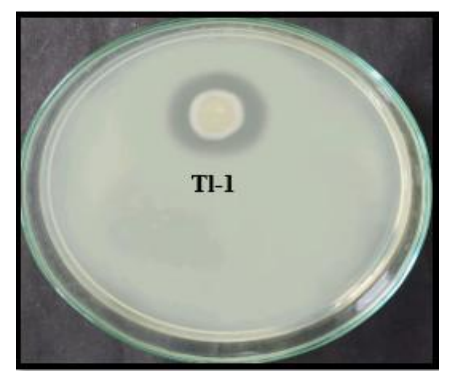

\section{Lytic enzyme}

\section{Protease activity}

Protease activity shown by bacterial isolates from the Tal site was expressed in the range of 6 to $14 \mathrm{~mm}$ in diameter of the clear zone around the bacterial growth on skim milk agar plate. Out of eleven isolates, seven isolates showed protease activity. Maximum activity was shown by Tl-7 (14 mm), followed by Tl-1 $(13 \mathrm{~mm})$ and Tl-8 $(11 \mathrm{~mm})$. From Tal, most of the isolates were found positive for protease activity (Table 5).

Protease is a hydrolytic enzyme which suppresses or inhibits the growth of the bacterial and fungal pathogens present in the rhizosphere of the plant. So, the protease production by rhizobacteria is an important attribute. All the isolates produced protease in good quantity. A similar study was reported by Upadyay et al., (2013). Some proteolytic enzymes, especially elastase and subtilisin, also possess bacteriolytic properties against different gram-positive and gram-negative bacteria.

In conclusion, a total of eleven isolates were recovered from the Tal site in the Hamirpur district of Himachal Pradesh. These isolates were isolated on King's B agar media. The pigmentation of colonies of bacterial isolates from Tal varied from white, cream, off-white and whitish-creamish. The majority of isolates were white $(55 \%)$ in color, $9 \%$ were cream in color, $27 \%$ of isolates were off-white and $9 \%$ were whitish-creamish in color. $73 \%$ were circular, $18 \%$ were punctiform and $9 \%$ were round in form. Out of total isolates, $46 \%$ of isolates were raised, $45 \%$ were flat, and $9 \%$ had convex elevation. $62 \%$ of isolates were entire, and $38 \%$ had undulating margins. $82 \%$ of the bacterial isolates were gram- negative, while $18 \%$ were found to be gram-positive. $82 \%$ of the isolates were bacilli and $18 \%$ had a cocci shape. Our results are in agreement with those from other investigations that found gram-negative bacteria as the main composition of the rhizosphere and rootassociated microbial communities in many plant species. P-solubilization was observed in eight isolates from the Tal site in Hamirpur district.Phosphorus is one of the most important elements for plant biological growth and development. The capacity of rhizobacteria to convert insoluble phosphorus (P) to an accessible form, such as orthophosphate, is a critical characteristic for improving plant development and production during a PGPB (Saharan and Nehra, 2011).Chemical fertilizers are the primary source of phosphorus in agricultural systems, although $\mathrm{Fe}, \mathrm{Ca} 2+$ complexes fix around 7590 percent of the phosphorus applied to the soil (Kumar et al., 2020). The most common mechanism of action implicated by PGPR for increasing nutrient availability to host plants is phosphate solubilization (Thakur et al., 2014). One isolate was discovered to have 
HCN activity, out of a total of eleven. Other isolates were less efficient in producing $\mathrm{HCN}$. The colour of the filter paper strip changed from brown to (+++) when Tl-1 was applied. Rhizobacterial species are involved in the synthesis of HCN and play an important role in biological pathogen control.

In the case of the lytic enzyme, all isolates were tested for protease activity, which has previously been shown in several isolates. Seven of the 11 isolates tested positive for protease activity. On skim milk agar, protease activity was measured in the range of 5-20 mm.

In vitro, this work shows that a functional PGPR plays a critical role in protease activity. It is stated that this is a fundamental study that has offered insight into the bacterial community found in Himachal Pradesh, India's mid-zone. In the present study discovered P-solubilizing, HCN-producing, and lytic enzyme (protease)-producing bacteria in the natural population.

\section{Acknowledgments}

Authors are thankful to Career Point University, Hamirpur (H.P.), India for funding the research work. Thanks, are also due to the Head, Division of Microbiology, Career Point University, Hamirpur (H.P.) for providing the necessary facilities required for conducting the research work.

\section{References}

Bhattacharyya, P. N. and Jha, D. K., 2012. Plant growth-promoting rhizobacteria (PGPR): emergence in agriculture. World Journal of Microbiology and Biotechnology, 28(4), pp.1327-1350.

Das, A. J., Kumar, M. and Kumar, R., 2013. Plant growth promoting rhizobacteria (PGPR): an alternative of chemical fertilizer for sustainable, environment friendly agriculture. Res J Agric For Sci, 1(4), pp.21-23.

Gupta, G., Parihar, S. S., Ahirwar, N. K., Snehi, S. K. and Singh, V., 2015. Plant growth promoting rhizobacteria (PGPR): current and future prospects for development of sustainable agriculture. $J$ Microb Biochem Technol, 7(2), pp.096-102.

Kumar, V., Sharma, N. and Kansal, S., 2019. Characterization of Potential PGPR's Isolated from Rhizosphere of Wheat from Trans-Himalayas and their Efficacy on seed germination and growth promotion of wheat under net house conditions. Journal of Plant Development Sciences Vol, 11(3), pp.121-131.

Kundan, R., Pant, G., Jadon, N. and Agrawal, P. K., 2015. Plant growth promoting rhizobacteria: mechanism and current prospective. J Fertil Pestic, 6(2), p.9.

Mangmang, J. S., Deaker, R. and Rogers, G., 2015. Azospirillum brasilense enhances recycling of fish effluent to support growth of tomato seedlings. Horticulturae, 1(1), pp.14-26.

Modi, K., Patel, P. and Parmar, K., 2017. Isolation, screening and characterization of PGPR from rhizosphere of rice. Int J Pure Appl Biosci, 5, pp.264-270.

Nelson, L. M., 2004. Plant growth promoting rhizobacteria (PGPR): Prospects for new inoculants. Crop management, 3(1), pp.1-7.

Oyewole, C. I., 1999. Effects of sowing method and rodent control on the yield and yield components of two varieties of wheat (Triticum aestivum L.) in Sokoto. An M. Sc (Doctoral dissertation, Dissertation presented to Post-graduate school, Usmanu Danfodiyo University, Sokoto 73pp).

Pikovskaya, R. I., 1948. Mobilization of 
phosphorus in soil in connection with vital activity of some microbial species. Mikrobiologiya, 17, pp.362370.

Saharan, B. S. and Nehra, V., 2011. Plant growth promoting rhizobacteria: a critical review. Life Sci Med Res, 21(1), p.30.

Shewry, P. R. and Hey, S. J., 2015. The contribution of wheat to human diet and health. Food and energy security, 4(3), pp.178-202.

Singh, Y. and Lal, N., 2016. Isolation and Characterization of PGPR from Wheat (Triticum aestivum) Rhizosphere and Their Plant Growth Promoting Traits in Vitro. Front. Microbiol., 6(198).

Tamilarasi, S., Nanthakumar, K., Karthikeyan, K. and Lakshmanaperumalsamy, P., 2007. Diversity of root associated microorganisms of selected medicinal plants and influence of rhizomicroorganisms on the antimicrobial property of Coriandrum sativum. Journal of environmental biology, 29(1), p.127.

Thakur, D., Kaushal, R. and Shyam, V., 2014. Phosphate solubilizing microorganisms: role in phosphorus nutrition of crop plants-a review.
Agricultural Reviews, 35(3), pp.159171.

Upadhyay, S. K., Singh, J. S. and Singh, D. P., 2011. Exopolysaccharide-producing plant growth-promoting rhizobacteria under salinity condition. Pedosphere, 21(2), pp.214-222.

Van Der Heijden, M. G., Bardgett, R. D. and Van Straalen, N. M., 2008. The unseen majority: soil microbes as drivers of plant diversity and productivity in terrestrial ecosystems. Ecology letters, 11(3), pp.296-310.

Vejan, P., Abdullah, R., Khadiran, T., Ismail, S. and Nasrulhaq Boyce, A., 2016. Role of plant growth promoting rhizobacteria in agricultural sustainability-a review. Molecules, 21(5), p.573.

Verma, M., Mishra, J. and Arora, N. K., 2019. Plant growth-promoting rhizobacteria: diversity and applications. In Environmental biotechnology: for sustainable future (pp. 129-173). Springer, Singapore.

Vijay, K., Nivedita, S. and Parmar, Y., 2017. Plant growth promoting rhizobacteria as growth promoters for wheat: a review. Agric Res Tech: Open Access $J$, 12(4), pp.555-857.

\section{How to cite this article:}

Vijay Kumar, Indu, Richa, Sahil Kumar and Diksha Sehajpal. 2021. Isolation and Screening of Plant Growth Promoting Rhizobacteria from the Rhizospheric Soil of Wheat (Triticum aestivum) from Lower Western Himalayan Zone of Himachal Pradesh. Int.J.Curr.Microbiol.App.Sci. 10(11): 23-34. doi: https://doi.org/10.20546/ijcmas.2021.1011.004 